\title{
Clinical evaluation of upper limb function: Patient's impairment, disability and health-related quality of life
}

\author{
Young Hak Roh* \\ Department of Orthopaedic Surgery, Gil Medical Center, Gachon University School of Medicine, Incheon, Korea
}

Musculoskeletal disorders substantially impacts physical activity, mental state, and quality of life (QOL). Generally, comprehensive assessment of upper limb function requires measures of impairment or disability as well as health-related quality of life. A growing number of outcome instrument have been introduced to evaluate upper limb function and disability, and these measures can be categorized as patient- or clinicianbased, and as condition specific or general health-related QOL evaluations. The upper limb outcome instruments reviewed in this article assess different aspect of upper limb conditions, and the measures are affected by differences in cultural, psychological, and gender aspect of illness perception and behavior. Therefore, physician should select/interpret the outcome instruments addressing their primary purpose of research. Information about regional instruments for upper limb condition and health-related $\mathrm{QOL}$ in upper limb disorder may help us in decision-making for treatment priority or in interpretation of the treatment outcomes.

Keywords: Upper limb, Outcome instrument, Impairment, Disability, Quality of life

\section{INTRODUCTION}

Musculoskeletal disorders are among the most frequently occurring chronic conditions that affect the general population and substantially impact physical activity, mental state, and quality of life (QOL) (Bingefors and Isacson, 2004; Lawrence et al., 1998). Musculoskeletal disorders become more prevalent with age, and they are the leading cause of disability (Lawrence et al., 2008; Picavet and Hazes, 2003). The management goals of patients with musculoskeletal disorders are no longer limited to reducing signs and symptoms but now includes increasing function (Dieppe, 2004). There is a current trend to enhance general well-being or QOL, which involves integrating patient-centric perspectives and comprehensive assessment of intervention outcomes (Furner et al., 2011; Gruber et al., 2010; Menz et al., 2010).

A growing number of outcome instruments have been introduced to evaluate upper limb function and disability (Oh et al., 2009; Romeo et al., 1996). These instruments range from objec- tive measures, such as range of motion (ROM) (Constant and Murley, 1987) or muscle strength (Constant and Murley, 1987; Roh et al., 2012e), to more subjective measures, such as patient satisfaction (Monnin and Perneger, 2002) or quality of life (Goldhahn et al., 2008; van de Ven-Stevens et al., 2009). Impairments such as muscle weakness or limitation in range of motion may have a comprehensive impact on daily life. For instance, grip strength has a critical role during the performance of daily activities, and is considered an important measure of recovery after upper extremity injuries and for the evaluation of treatment outcomes. However, the degree of satisfaction regarding function or disability differs across patients, and this inter-patient variability in self-assessment is important to consider in the clinical evaluation of upper limb function. In clinical studies, recent trend has been to move toward patient-based (patient-centric) instruments and away from clinician-based (performance based) ones, the letter of which is more susceptible to observer bias and error and does not represent illness/ disability experience of patients themselves (Harvie et al., 2005).
${ }^{*}$ Corresponding author: Young Hak Roh

Department of Orthopaedic Surgery, Gil Medical Center, Gachon University School of Medicine, 21 Namdong-daero 774 beon-gil, Namdong-gu, Incheon 405-760, Korea Tel: +82-32-460-8916, Fax: +82-32-468-5437, E-mail: ryhak@hanmail.net

Received: August 23, 2013 / Revised: August 25, 2013 / Accepted: August 25, 2013
This is an Open Access article distributed under the terms of the Creative Commons Attribution Non-Commercial License (http://creativecommons.org/licenses/by-nc/3.0/) which permits unrestricted non-commercial use, distribution, and reproduction in any medium, provided the original work is properly cited. 
Furthermore, outcome assessments include measures of impairment or disability as well as measures of general health-related QOL, in order to assess the full impact of problem related to a certain upper limb condition.

There are many outcome instruments available for assessment of upper limb functions. These are not standardized or unclear. The purpose of this paper is to review outcome measures of upper limb function, which can be categorized as patient- or clinicianbased, and as condition specific or general health related QOL evaluations. In addition, we discuss clinical research considerations in selection/interpretation of instruments for upper limb functions. The upper limb outcome instruments reviewed in this article include the Michigan hand questionnaire (MHQ), the Patient-rated wrist evaluation score (PRWE), the Constant-Murley score, the simple shoulder test (SST) the Oxford shoulder score (OSS,) the disability of arm, shoulder and hand questionnaire (DASH), and the short form- 36 health survey (SF-36).

\section{OUTCOME INSTRUMENTS IN PATIENT WITH UPPER LIMB CONDITION}

On one hand, condition-specific instruments of musculoskeletal disorders measure symptoms and disabilities relevant to specific conditions and are useful for assessing responses to treatments. On the other hand, general health status instruments measure multiple aspects of health, including physical function, mental health, and social function. Although generic measures may not be as sensitive to the disability experienced by patients, general health status measurements generally correlate with condition-specific instruments that address musculoskeletal manifestation (Ostendorf et al., 2004; SooHoo et al., 2002). This implies that musculoskeletal complaints influence general health status and that a considerable proportion of variation in general health status can be attributed to regional musculoskeletal disability.

\section{Hand \& Wrist}

The Michigan hand questionnaire (MHQ) is a hand specific and patient-based subjective assessment (Chung et al., 1998). The questionnaire assesses a patient's perception to function, pain, satisfaction, and aesthetic appearance. The original MHQ has been used with almost all types of hand disorders, and its reliability, validity, and responsiveness has been validated for a range of upper extremity conditions, such as carpal tunnel syndrome, distal radius fractures, and rheumatoid arthritis (Chatterjee and Price, 2009; Kotsis et al., 2007; Roh et al., 2011; Waljee et al., 2010). The questionnaire itself consists of 57 items, and distinguishes between left and right hands over six domains, including overall hand function, activities of daily living, pain, work performance, aesthetics, and patient satisfaction with function. Each domain is scored from 0 to 100, by which a lower score denotes worse disability save except for the pain domain for which the opposite holds true. The final score is obtained by averaging the six scores after reversing the pain score.

Patient-rated wrist evaluation score (PRWE) is a reliable and valid tool for quantifying patient-rated wrist pain and disability in the setting of distal radius fractures treatment (MacDermid et al., 1998). The questionnaire is completed by the patient themselves and consists of two domains, pain and function. There are five items in the pain domain and ten items in the function domain. The response to each item is scored on a scale of 0-10. The pain score is the sum of five items, with the worst possible score of 50 , and the disability (function) score is the sum of ten items divided by 2 .

\section{Shoulder}

The Constant-Murley questionnaire is a shoulder specific and clinician-based assessment with acceptable reliability and validity (Gilbart and Gerber, 2007), and is the most widely used questionnaire in Europe (Kirkley et al., 2003). This instrument consists of 4 function items and 5 physical examination items. As the measurements are fundamentally different, the functional and physical examinations are scored separately, as opposed to being combined for a total score.

The simple shoulder test (SST) is a patient-based measure (Lippitt, 1993). It is a quick, subjective questionnaire composed of 12 questions with yes or no response. It was reported to be reliable, valid, and responsive (Godfrey et al., 2007). For each question, a patient indicates whether he or she is able to perform the indicated activity or not. The sum total score ranges from 0 (worst) to 12 (best) for shoulder function.

Oxford shoulder score (OSS) (Dawson et al., 1996) is a shoulderspecific, patient-based questionnaire composed of 12 questions for assessing pain perception and quality of life in patients with symptomatic pathologies of the shoulder. Each question on the questionnaire is scored 0-4, with four representing the best. Thus, it produces overall scores that range from 0 to 48 , with 48 being the best outcome. The Oxford shoulder score is easy to complete, imposes very little burden to the patient, and provides reliable, valid, 
and responsive data about patient perceptions of shoulder problems (Christie et al., 2009; Kirkley et al., 2003). It is an internationally recognized orthopedic assessment instrument, is available in certain European languages. Its validity has been demonstrated through cross-cultural adaptation processes. (Berendes et al., 2010, Huber et al., 2004; Murena et al., 2010; Roh et al., 2012c)

\section{Whole upper extremity}

The disability of arm, shoulder and hand (DASH) is a self-administered, upper-extremity specific questionnaire that consists of 30 questions (Hudak et al., 1996). It includes physical functions, symptoms, and social function, work, sleep, and confidence items. Five responses are provided per question and are scored from 1 (without difficulty or no symptom) to 5 (unable to engage in activity or very severe symptom). Thus, the DASH provides the best possible score of 0 and the worst possible score of 100 . The DASH evaluation is user- friendly, reliable, and valid for a range of upper-extremity disorders (Gummesson et al., 2003; Szabo, 2001), and is the best instrument for evaluating patients with disorders involving multiple upper limb joints.

\section{Generic health status measure}

The short form - 36 (SF-36) health survey is the most widely used, patient-reported generic health status measure (Ware and Sherbourne, 1992). The 36 items in the questionnaire are grouped by eight health subscales which are designed to represent the World Health Organization definition of health: physical function (PF), role limitations due to physical problems (RP), bodily pain (BP), general health $(\mathrm{GH})$, vitality (VT), social function (SF), role limitations due to emotional problems (RE), and mental health (MH). These eight scales can be combined into two summary measures that provide overall estimates of physical health (physical component summary [PCS]) and mental health (mental component summary [MCS]). The SF36V2 uses norm-based scores, and the its summary scores use the sum of eight subscale z-scores weighted by factor score coefficients (Ware, 2000). The SF-36 is commonly used to represent broad aspects of health for questionnaire validation and reportedly is more responsive than other general health instruments for musculoskeletal disorders (Beaton et al., 1996).

\section{CONSIDERATIONS IN THE SELECTION/ INTERPRETATION OF INSTRUMENTS}

To evaluate upper limb impairment or disability, reliable and validated outcome measures should take into account all aspects of a patient's life that may be affected by the presence of the disability or impairment. Most investigators support the use of condition specific measures along with generic measures. The former include items relevant and sensitive to the disorder being studied, and the latter allow for comparisons between conditions and may be sensitive to unexpected consequences of a disorder. Investigators should select a proper instrument with established validity and reliability. All things being equal, the most responsive instrument available should be used in order to minimize the sample size for the proposed study. Therefore, additional information is required to understand how sensitive these instruments are to clinical change in function experienced by patients who have problems over time.

Psychologic distress, such as pain-induced anxiety or depression, is increasingly recognized as contributing to pain and disability perception in several musculoskeletal disorders (Kim et al., 2011; Roh et al., 2012d). Depression has been reported to be highly prevalent in the elderly and consistently contributes to symptom severity in some musculoskeletal disorders (Roh et al., 2012b; Rosemann et al., 2007; Salaffi et al., 1991) Furthermore, subjective factors, such as pain and depression, have been reported to have greater influences when disability is measured with respect to functions related to the entire upper extremity, i.e. DASH scores, rather than with respect to a more specific regional site (Lindenhovius et al., 2008). A large variability in DASH scores in upper-extremity disorders was found to arise from psychosocial rather than physical factors (Ring et al., 2006).

Female subjects are known to report higher level of musculoskeletal pain and disability, although objective findings, such as range of motion and abduction strength, did not differ between the genders (Roh et al., 2012a; Roh et al., 2012d). Musculoskeletal pain or disability has been reported to be both more prevalent (Leveille et al., 2005) and worse in women (Bingefors and Isacson, 2004), which could be due to a higher physical vulnerability (Wijnhoven et al., 2006) or sensitivity to pain (Wolfe et al., 1995) in the gender. This gender-specific effect was reported not to be confined to a specific physical subscale but rather involved all physical components of SF- 36 and DASH.

Functional assessment is also influenced by the prevalence of degenerative musculoskeletal disorders such as osteoarthritis and rotator cuff disease. In individuals older than $65 \mathrm{yr}$, osteoarthritis of the knees and hands and rotator cuff diseases are the most prevalent causes of musculoskeletal pain. A high prevalence of these degenerative musculoskeletal diseases has been previously demonstrated (Picavet and Hazes, 2003), and prevalence of concurrent 
upper and lower extremity pain in those older than $65 \mathrm{yr}$ is estimated to be greater than $40 \%$ (Scudds and Robertson, 2000).

\section{CONCLUSIONS}

Much progress has been made in validation of functional assessment of upper limb conditions, and currently there is a growing number of instruments for each of the main groups of upper limb conditions. The upper limb instruments reviewed in this article allow for assessments of various aspects of functional problems related to upper limb conditions. Furthermore, functional outcome measures of upper limb are affected by differences in cultural, psychological, and gender aspects of illness perception and behavior. Therefore, comprehensive assessment of upper limb function requires measures of impairment or disability as well as generic measures of health-related QOL. Standardized assessments of regional musculoskeletal disabilities and general health status may help clinician in treatment decision-making and in interpretation of treatment outcomes of upper limb conditions. Clinicians and researchers should be aware of the characteristics of each outcome instrument and select the upper limb outcome instruments which most appropriately address the primary purpose of a given research.

\section{CONFLICT OF INTEREST}

No potential conflict of interest relevant to this article was reported.

\section{REFERENCES}

Beaton DE, Bombardier C, Hogg-Johnson SA. Measuring health in injured workers: a cross-sectional comparison of five generic health status instruments in workers with musculoskeletal injuries. Am J Ind Med 1996;29:618-631.

Berendes T, Pilot P, Willems J, Verburg H, te Slaa R. Validation of the Dutch version of the Oxford Shoulder Score. J Shoulder Elbow Surg 2010;19: 829-836.

Bingefors K, Isacson D. Epidemiology, co-morbidity, and impact on healthrelated quality of life of self-reported headache and musculoskeletal pain--a gender perspective. Eur J Pain 2004;8:435-450.

Chatterjee JS, Price PE. Comparative responsiveness of the Michigan Hand Outcomes Questionnaire and the Carpal Tunnel Questionnaire after carpal tunnel release. J Hand Surg Am 2009;34:273-280.

Christie A, Hagen KB, Mowinckel P, Dagfinrud H. Methodological properties of six shoulder disability measures in patients with rheumatic diseases referred for shoulder surgery. J Shoulder Elbow Surg 2009; 18:89-95.

Chung KC, Pillsbury MS, Walters MR, Hayward RA. Reliability and validity testing of the Michigan Hand Outcomes Questionnaire. J Hand Surg Am 1998;23:575-587.

Constant CR, Murley AH. A clinical method of functional assessment of the shoulder. Clin Orthop Relat Res 1987:160-164.

Dawson J, Fitzpatrick R, Carr A. Questionnaire on the perceptions of patients about shoulder surgery. J Bone Joint Surg Br 1996;78:593-600.

Dieppe PA. Relationship between symptoms and structural change in osteoarthritis. what are the important targets for osteoarthritis therapy? J Rheumatol Suppl 2004;70:50-53.

Furner SE, Hootman JM, Helmick CG, Bolen J, Zack MM. Health-related quality of life of US adults with arthritis: analysis of data from the behavioral risk factor surveillance system, 2003, 2005, and 2007. Arthritis Care Res (Hoboken) 2011;63:788-799.

Gilbart MK, Gerber C. Comparison of the subjective shoulder value and the Constant score. J Shoulder Elbow Surg 2007;16:717-721.

Godfrey J, Hamman R, Lowenstein S, Briggs K, Kocher M. Reliability, validity, and responsiveness of the simple shoulder test: psychometric properties by age and injury type. J Shoulder Elbow Surg 2007;16:260267.

Goldhahn J, Angst F, Simmen BR. What counts: outcome assessment after distal radius fractures in aged patients. J Orthop Trauma 2008;22:S126130.

Gruber G, Zacherl M, Giessauf C, Glehr M, Fuerst F, Liebmann W, Gruber K, Bernhardt GA. Quality of life after volar plate fixation of articular fractures of the distal part of the radius. J Bone Joint Surg Am 2010; 92:1170-1178.

Gummesson C, Atroshi I, Ekdahl C. The disabilities of the arm, shoulder and hand (DASH) outcome questionnaire: longitudinal construct validity and measuring self-rated health change after surgery. BMC Musculoskelet Disord 2003;4:11.

Harvie P, Pollard TC, Chennagiri RJ, Carr AJ. The use of outcome scores in surgery of the shoulder. J Bone Joint Surg Br 2005;87:151-154.

Huber W, Hofstaetter JG, Hanslik-Schnabel B, Posch M, Wurnig C. The German version of the Oxford Shoulder Score--cross-cultural adaptation and validation. Arch Orthop Trauma Surg 2004;124:531-536.

Hudak PL, Amadio PC, Bombardier C. Development of an upper extremity outcome measure: the DASH (disabilities of the arm, shoulder and hand) [corrected]. The Upper Extremity Collaborative Group (UECG). Am J Ind Med 1996;29:602-608.

Kim KW, Han JW, Cho HJ, Chang CB, Park JH, Lee JJ, Lee SB, Seong SC, Kim TK. Association between comorbid depression and osteoarthritis symptom severity in patients with knee osteoarthritis. J Bone Joint 
Surg Am 2011;93:556-563.

Kirkley A, Griffin S, Dainty K. Scoring systems for the functional assessment of the shoulder. Arthroscopy 2003;19:1109-1120.

Kotsis SV, Lau FH, Chung KC. Responsiveness of the Michigan Hand Outcomes Questionnaire and physical measurements in outcome studies of distal radius fracture treatment. J Hand Surg Am 2007;32:84-90.

Lawrence RC, Felson DT, Helmick CG, Arnold LM, Choi H, Deyo RA, Gabriel S, Hirsch R, Hochberg MC, Hunder GG, Jordan JM, Katz JN, Kremers HM, Wolfe F. Estimates of the prevalence of arthritis and other rheumatic conditions in the United States. Part II. Arthritis Rheum 2008:58:26-35.

Lawrence RC, Helmick CG, Arnett FC, Deyo RA, Felson DT, Giannini EH, Heyse SP, Hirsch R, Hochberg MC, Hunder GG, Liang MH, Pillemer SR, Steen VD, Wolfe F. Estimates of the prevalence of arthritis and selected musculoskeletal disorders in the United States. Arthritis Rheum 1998;41:778-799.

Leveille SG, Zhang Y, McMullen W, Kelly-Hayes M, Felson DT. Sex differences in musculoskeletal pain in older adults. Pain 2005;116:332-338.

Lindenhovius AL, Buijze GA, Kloen P, Ring DC. Correspondence between perceived disability and objective physical impairment after elbow trauma. J Bone Joint Surg Am 2008;90:2090-2097.

Lippitt SB, Matsen FA 1993. A practical tool for evaluating function: the Simple Shoulder Test. In: Masten FA, Fu FH, Hawkins RJ (ed.) The Shoulder: A Balance of Mobility and Stability. Rosemont, Ill: American Academy of Orthopedic Surgeons.

MacDermid JC, Turgeon T, Richards RS, Beadle M, Roth JH. Patient rating of wrist pain and disability: a reliable and valid measurement tool. J Orthop Trauma 1998;12:577-586.

Menz HB, Roddy E, Thomas E, Croft PR. Impact of hallux valgus severity on general and foot-specific health-related quality of life. Arthritis Care Res (Hoboken) 2010.

Monnin D, Perneger TV. Scale to measure patient satisfaction with physical therapy. Phys Ther 2002;82:682-691.

Murena L, Vulcano E, D’Angelo F, Monti M, Cherubino P. Italian cross-cultural adaptation and validation of the Oxford Shoulder Score. J Shoulder Elbow Surg 2010;19:335-341.

Oh JH, Jo KH, Kim WS, Gong HS, Han SG, Kim YH. Comparative evaluation of the measurement properties of various shoulder outcome instruments. Am J Sports Med 2009;37:1161-1168.

Ostendorf M, van Stel HF, Buskens E, Schrijvers AJ, Marting LN, Verbout AJ, Dhert WJ. Patient-reported outcome in total hip replacement. A comparison of five instruments of health status. J Bone Joint Surg Br 2004; 86:801-808.

Picavet HS, Hazes JM. Prevalence of self reported musculoskeletal diseases is high. Ann Rheum Dis 2003;62:644-650.
Ring D, Kadzielski J, Fabian L, Zurakowski D, Malhotra LR, Jupiter JB. Selfreported upper extremity health status correlates with depression. J Bone Joint Surg Am 2006;88:1983-1988.

Roh YH, Kim KW, Paik NJ, Kim TK, Gong HS. How much are upper or lower extremity disabilities associated with general health status in the elderly? Clin Orthop Relat Res 2012a;470:3246-3252.

Roh YH, Lee BK, Noh JH, Oh JH, Gong HS, Baek GH. Effect of depressive symptoms on perceived disability in patients with chronic shoulder pain. Arch Orthop Trauma Surg 2012b;132:1251-1257.

Roh YH, Noh JH, Kim W, Oh JH, Gong HS, Baek GH. Cross-cultural adaptation and validation of the Korean version of the Oxford shoulder score. Arch Orthop Trauma Surg 2012c;132:93-99.

Roh YH, Noh JH, Oh JH, Baek GH, Gong HS. To what degree do shoulder outcome instruments reflect patients' psychologic distress? Clin Orthop Relat Res 2012d;470:3470-3477.

Roh YH, Yang BK, Noh JH, Baek GH, Song CH, Gong HS. Cross-cultural adaptation and validation of the Korean version of the Michigan hand questionnaire. J Hand Surg Am 2011;36:1497-1503.

Roh YH, Yi SR, Noh JH, Lee SY, Oh JH, Gong HS, Baek GH. Intra-articular corticosteroid injection in diabetic patients with adhesive capsulitis: a randomized controlled trial. Knee Surg Sports Traumatol Arthrosc 2012e;20:1947-1952.

Romeo AA, Bach BR Jr, O'Halloran KL. Scoring systems for shoulder conditions. Am J Sports Med 1996;24:472-476.

Rosemann T, Backenstrass M, Joest K, Rosemann A, Szecsenyi J, Laux G. Predictors of depression in a sample of 1,021 primary care patients with osteoarthritis. Arthritis Rheum 2007;57:415-422.

Salaffi F, Cavalieri F, Nolli M, Ferraccioli G. Analysis of disability in knee osteoarthritis. Relationship with age and psychological variables but not with radiographic score. J Rheumatol 1991;18:1581-1586.

Scudds RJ, Robertson JM. Pain factors associated with physical disability in a sample of community-dwelling senior citizens. J Gerontol A Biol Sci Med Sci 2000;55:M393-399.

SooHoo NF, McDonald AP, Seiler JG, 3rd McGillivary GR. Evaluation of the construct validity of the DASH questionnaire by correlation to the SF-36. J Hand Surg Am 2002;27:537-541.

Szabo RM. Outcomes assessment in hand surgery: when are they meaningful? J Hand Surg Am 2001;26:993-1002.

van de Ven-Stevens LA, Munneke M, Terwee CB, Spauwen PH, van der Linde $\mathrm{H}$. Clinimetric properties of instruments to assess activities in patients with hand injury: a systematic review of the literature. Arch Phys Med Rehabil 2009;90:151-169.

Waljee JF, Chung KC, Kim HM, Burns PB, Burke FD, Wilgis EF, Fox DA. Validity and responsiveness of the Michigan Hand Questionnaire in patients with rheumatoid arthritis: a multicenter, international study. 
Arthritis Care Res (Hoboken) 2010;62:1569-1577.

Ware JE Jr. SF-36 health survey update. Spine (Phila Pa 1976) 2000;25:31303139.

Ware JE Jr, Sherbourne CD. The MOS 36-item short-form health survey (SF-36). I. Conceptual framework and item selection. Med Care 1992; 30:473-483.
Wijnhoven HA, de Vet HC, Picavet HS. Prevalence of musculoskeletal disorders is systematically higher in women than in men. Clin J Pain 2006; 22:717-724.

Wolfe F, Ross K, Anderson J, Russell IJ. Aspects of fibromyalgia in the general population: sex, pain threshold, and fibromyalgia symptoms. J Rheumatol 1995;22:151-156. 